\title{
Penerapan Inovasi Pelayanan Publik GO-DOK Di Kota Tasikmalaya
}

\author{
${ }^{1}$ Tania Firda Anggraini Maruao, ${ }^{2}$ Pirman Maolana, ${ }^{3}$ Asri Hidayani, ${ }^{4}$ Cepi Sandra \\ Wijaya, ${ }^{5}$ Fikri Ardiansyah
}

\begin{abstract}
${ }^{1}$ STIA YPPT Priatim Tasikmalaya, Indonesia; anggrainitan07@gmail.com ${ }^{2}$ STIA YPPT Priatim Tasikmalaya, Indonesia; firmanmaolana084@gmail.com ${ }^{3}$ STIA YPPT Priatim Tasikmalaya, Indonesia; asrihidayani01@gmail.com ${ }^{4}$ STIA YPPT Priatim Tasikmalaya, Indonesia; cepisandra30@gmail.com ${ }^{5}$ STIA YPPT Priatim Tasikmalaya, Indonesia; ardiansyahfikri18@gmail.com
\end{abstract}

\begin{abstract}
Demands for public service innovation are increasingly pressing along with the increasing awareness that the community has the right to be served and the government has an obligation to provide the best service. One of the services provided by the government to the community is population administration services. In this case the researcher examines how the GO-DOK service innovation is applied. This research uses qualitative methods and descriptive approaches. This study uses public service theory and public service innovation. Determination of implementing informants using snowball sampling and user informants using purposive sampling. The latest innovation service presented by the City of Tasikmalaya government in the use of digital-based efforts to facilitate the community, especially in population administration services in the City of Tasikmalaya. With a delivery service developed by the Disdukcapil of Tasikmalaya City.
\end{abstract}

Keywords: Public Service, Service Innovation, Local Government, GO-DOK.

\section{Pendahuluan}

Ditengah permasalahan Indonesia yang kian kompleks ini, banyak bermunculan berbagai ide penanganan baik yang bersipat sektoral maupun secara general. Salah satunya dengan adanya revolusi mental yang di masa pemerintahan presiden Joko Widodo ini telah menjadi tageline pemerintahan yang terus menggema dengan menciptakan paradigma baru dalam penyelenggaran pemerintahan. Hal tersebut dapat dilihat dari dikeluarkannya Instruksi Presiden No.12 tahun 2016 tentang Gerakan Nasional Revolusi Mental (GNRM), yaitu dengan maksud agar sikap dan karakter setiap anak bangsa dapat dibanguncsesuai dengan nilai nilai luhur kebangsaan. Adapun menurut Inpres tersebut, terdapat setidaknya lima program nasional yang salah satunya adalah Program Gerakan Indonesia Melayani dengan memfokuskan pada penyempurnaan standar pelayanan publik dan pelayanan yang inovatif. Hal tersebut sejalan dengan permasalah pelayanan publik pada saat ini yang masih lamban dan menguras waktu yang lama serta jalur birokrasinya yang berberlit berlit.

Pada dasarnya, pelayanan publik (public services) merupakan suatu pelayanan yang diberikan pemerintah suatu Negara sebagai bentuk tanggung jawabnya untuk memenuhi kebutuhan masyarakat. Saat ini, kondisi penyelenggaraan pelayanan publik di setiap negara tentunya tidak sama dan tidak sesederhana sebagaimana yang terjadi sebelumnya. Hal tersebut didasari oleh sebuah realitas bahwa kebutuhan dan tantangan yang dihadapi masyarakat juga pemerintah semakin kompleks dan beragam. Menurut Sinambela dalam (Junior, 2016) pelayanan publik ialah usaha dalam memenuhi kebutuhan dan keinginan setiap lapisan masyarakat yang diselenggarakan oleh aparatur negara. Pelayanan publik juga dimaknai sebagai usaha untuk memberikan dan menyediakan pelayanan terhadap segenap elemen masyarakat yang melekat pada dirinya sejumlah kebutuhan sesuai dengan ketetapan hukum dan peraturan lainnya (Kurniawan, 2005). 
Farnham dan Horton (1993) selanjutnya menjelaskan bahwa pelayanan publik didefinisikan secara luas sebagai organisasi sektor publik yang pengeluaran dan belanja modalnya didanai oleh perpajakan, dibandingkan dengan meningkatkan pendapatan melalui penjualan layanan kepada pelanggan individual maupun korporasi. Sedangkan Spicker (2009) menerangkan pelayanan publik kedalam 3 arti, yaitu segala aktivitas pemerintah di dalam domain publik, mengatur dan mengurusi setiap urusan sosial masyarakat, dan dilakukan dengan tujuan untuk kebermanfaatan publik. Adapun Jordan (2006) mendefinisikasn pelayanan publik sebagai pemberian layanan baik itu jasa maupun barang terhadap setiap anggota masyarakat seperti individu, keluarga, dan kelompok masyarakat. Kemudian secara lebih konkrit, Pemerintah melalui UU No. 25 Tahun 2009 mengartikan pelayanan publik sebagai rangkaian kegiatan yang diselenggarakan dalam rangka agar kebutuhan atau kepentingan pelayanan terpenuhi sesuai dengan aturan hukum yang berlaku untuk masing-masing warga negara dan penduduk atas barang, jasa, dan/atau pelayanan administratif yang dihadirkan oleh para penyelenggara pelayanan publik. Penyelenggara pelayanan public merupakan institusi penyelenggara negara, korporasi, lembaga independen atau badan hukum yang dibentuk berdasarkan undang-undang atau hukum lain untuk kegiatan pelayanan publik.

Sinambela dalam (Junior, 2016) juga mengumukanan indikator indikator yang digunakan untuk melihat apakah pelayanan publik yang di berikan adalah pelayanan yang prima atau tidak yaitu antara lain transparansi, akuntabilitas, partisipatif, kesamaan hak, dan keseimbangan hak dan kewajiban. Untuk memberikan pelayan yang prima tentunya pemerintah perlu mengenali kebutuhan masyarakat. Hal tersebut dimaksudkan agar kepuasan masyarakat dapat meningkat dan agar pemerintah juga mampu adaptif dan responsif pada perubahan era saat ini. Salah satu kebutuhan masyarakat yang berkaitan dengan era global yang semakin maju ini adalah dengan mampu menguasai dan menerapkan teknologi informasi dalam proses birokrasi. Hal ini bertujuan agar mempercepat dan mempermudah pelaksanaan pelayanan publik sehingga menghasilkan cara kerja birokrasi yang baru.

Cara kerja birokrasi baru tersebut secara lebih sederhana dapat disamakan dengan Inovasi pelayanan. Inovasi umumnya berkaitan dengan proses, produk, prosedur, atau penciptaan hasil (Abernathy, et at, 1983). Inovasi juga berarti pengenalan sesuatu yang baru atau pembaharuan dan penemuan baru yang berbeda atau yang sudah ada sebelumnya. Amabile et al. dalam (Mirnasari, 2013) mendifinisikan inovasi sebagai proses perubahan atau memperkenalkan sesuatu yang baru. Lyndon (2007) menilai bahwa inovasi secara umum dimanfaatkan sebagai sebuah introduksi terhadap hal-hal baru yang bersifat prinsip maupun teknis dalam organisasi. Adapun menurut Rogers (2003) inovasi memiliki arti sebagai suatu gagasan, sesuatu yang bersifat praktik, maupun objek yang dipandang baru oleh individu ataupun kelompok lainnya.

Menurut Hellriegel dan Slocum (dalam Winardi, 2010), didalam lembaga publik inovasi kerap dimaknai sebagai perubahan organisasi yang senantiasa adaptif terhadap kondisi dan situasi di lingkungan sekitarnya dan untuk mengubah perilaku pegawai di organisasi tersebut. Sebagaimana dikatakan oleh Rogers (1983) bahwa inovasi pelayanan publik memiliki beberapa karakteristrik diantaranya yaitu:

1. Relative Advantage, yaitu bahwa sesuatu itu dapat dikatakan inovasi tatkala mempunyai beberapa kelebihan dan nilai tambah (added value) dibandingkan dengan kondisi sebelumnya.

2. Compatibility, yaitu bahwa inovasi juga harus memiliki kesesuaian dengan inovasi yang sebelumnya digantikan 
3. Complexity, yaitu bahwa inovasi tentunya memiliki kerumitan dengan tingkat yang lebih tinggi dari yang sebelumnya diterapkan. Tetapi karena inovasi menawarkan ide atau metode yang lebih baik sehingga kerumitan ini tidak menjadi sebuah masalah

4. Trialability, yaitu inovasi yang baru tentunya akan dapat diterima setelah melalui fase uji coba untuk mengukur inovasi tersebut setelah memiliki nilai yang dapat diterima oleh publik.

5. Observability, yaitu bahwa suatu inovasi akan dinilai dan terlihat oleh orang lain sejauh mana signifikansinya dalam suatu organisasi, dan semakin mudah bagi individu untuk melihat sebuah hasilnya semakin besar kemungkinan mereka untuk mengadopsi.

Menurut (Muluk, 2008) ada beberapa jenis inovasi pada pelayanan sektor publik, yaitu:

1. Inovasi Dalam Produk Pelayanan

Ini mengandung makna bahwa inovasi terjadi karena terjadi suatu perubahan desain maupun produk dari sebuah pelayanan, dan hal tersebut menimbulkan sejumlah perbedaan dengan yang sebelumnya.

2. Inovasi Dalam Proses Pelayanan

Ini mengandung arti bahwa inovasi akan mengacu pada pembaharuan kualitas yang berkelanjutan antara prosedur, kebijakan dan pengorganisasian yang diperlukan.

3. Inovasi Metode Pelayanan

Inovasi ini merujuk pada aspek sistem interaksi ketika aktivitas pelayanan dilakukan.

4. Inovasi Strategi dan Kebijakan Pelayanan

Inovasi ini lebih menekankan pada aspek visi, misi, tujuan yang realitas sehingga membutuhkan strategi yang baru.

\section{Inovasi Sistem Pelayanan}

Inovasi ini adanya pembahruan dalam konteks interaksi dengan pihak lain dalam pengelolaan organisasi.

Tuntutan terhadap inovasi pelayanan publik kian hari kian mendesak mengingat bahwa kesadaran masyarakat semakin meningkat akan hak-haknya untuk dilayani dan pemerintah memiliki kewajiban utuk memberikan pelayanan yang terbaik. Salah satu pelayanan yang di berikan pemerintah kepada masyarakat yaitu pelayanan administrasi kependudukan karena data dan informasi kependudukan merupakan salah satu aspek penting dalam mendukung pembangunan di suatu wilayah. Data yang digunakan sebagai acuan dalam pembangunan, evaluasi dan juga pengawasan pembangunan serta memperkirakan resiko dan hambatan dalam pembangunan. Manusia sebagai subjek sekaligus objek pembangunan perlu di ketahui demografinya. Setiap warga memerlukan pengakuan dari negara dengan memiliki data kependudukannya sendiri yang diatur oleh pemerintah dalam administrasi kependudukan.

Pelayanan administrasi kependudukan merupakan pelayanan publik yang menyentuh seluruh warga negara meskipun masih banyak terdapat keluhan karena banyaknya jumlah warga yang harus di layani dan juga banyak ragam dokumen yang berkaitan dengan administrasi kependudukan dan cacatan sipil. Dalam menyikapi masalah tersebut penyelenggaraan pelayanan publik di tuntut untuk lebih ekstra dan lebih inovatif untuk memungkinkan terselenggaranya pelayan dengan jalur birokrasi yang lebih ringkas, cepat serta 
efisien. Di era digital yang semakin maju ini pemerintah harus lebih adaptif serta tanggap dalam memanfaatkan teknologi yang ada. Begitu pula dengan penyelenggaraan dokumen administrasi kependudukan yang harus selalu berinovasi untuk menemukan strategi yang lebih baik untuk mengentaskan permasalahan birokrasi ini.

Terkait dengan pentingnya pelayanan publik dalam urusan pengadministrasian kependudukan seperti pembuatan identitas diri masyarakat, maka Dinas Kependudukan dan Pencatatan Sipil (Disdukcapil) Kota Tasikmalaya telah melakukan inovasi pelayanan berupa layanan GO-DOK (Go Dokumen Kependudukan). Pelayanan GO-DOK ini dilakukan dengan maksud untuk menyederhanakan pengurusan administrasi kependudukan hanya dengan mengirim pesan ke nomor WhatsApp Disdukcapil dengan melampirkan syarat syarat yang dibutuhkan. Apabila dilihat dari beberapa uraian diatas, peneliti kemudian merasa tertarik untuk lebih mengetahui mengenai penerapan GO-DOK dalam pelayan administrasi kependudukan di Dinas Kependudukan dan Catatan Sipil dan bagaimana strategi pengembangan inovasi pelayanan GO-DOK yang diterapkan oleh Dinas Kependudukan dan Catatan Sipil kota Tasikmalaya.

\section{Metode Penelitian}

Dalam melakukan penelitian ini, pendekatan kualitatif dengan jenis penelitian deskriptif kemudian digunakan. Melalui penelitian kualitatif ini peneliti melakukan aktivitas pengumpulan sejumlah data dalam bentuk kata maupun gambar. Data tersebut mencakup transkip wawancara, cacatan lapangan, serta dokumentasi lainnya. Adapun tujuannya untuk memahami bagaimana penerapan dan strategi pengembangan dari inovasi pelayanan publik GO-DOK di Dinas Kependudukan dan Catatan Sipil di Kota Tasikmalaya. Penentuan informan pelaksana menggunakan snowball sampling dan informan pengguna menggunakan purposive sampling. Adapun teknik pengumpulan data penelitian ini mengunakan studi kepustakaan dan wawancara. Jenis data yang digunakan merupakan data primer dan sekunder. Data primer yang diperoleh berasal dari narasumber di Disdukcapil Kota Tasikmalaya dengan menggunakan teknik wawancara serta sejumlah dokumen yang berkaitan dengan judul penelitian. Sedangkan data sekunder berasal dari studi pustaka yang diperoleh berdasar pada beberapa informasi hasil telusuran media daring.

\section{Hasil Dan Pembahasan}

Dalam rangka tertib administrasi dalam penataan kelembagaan serta meninggkatkan pelayanan kepada masyarakat, maka Disdukcapil Kota Tasikmalaya memiliki sejumlah tugas pokok dan fungsi (tupoksi) dalam usahanya membantu Kepala Daerah. Tugas tersebut yaitu menyelenggarakan berbagai macam urusan pemerintahan serta dan tugasnya dalam membantu kegiatan administrasi kependudukan dan pencatatan sipil. Adapun penerapan inovasi pelayanan ini dilihat dari karakteristik inovasi sebagaimana yang telah diuraikan sebelumnya.

\section{a. Relative Advantage (kemanfaatan)}

Progam inovasi pelayana GoDok tentunya harus memiliki keuntungan atau ke unggulan di bandingkan inovasi sebelumnya yang di terapkan oleh pemeritah dalam hal ini yaitu dinas kependudukan dan pencatatan sipil kota Tasikmalaya dengan adanya program inovasi pelayanan Go Dok ini memudahkan masyarakat dalam mengurus administrasi kependudukan dengan hanya melalui pengiriman berkas secara langsung melalui nomor Whatsapp Disdukcapil tanpa harus ke kantor kecamatan atau kantor Disdukcapil dan melalui proses antrian terlebih dahulu. Layanan ini diproses di disduk akan selesai dalam 1 jam paling lambat 
dalam 24 jam setelah melakukan pengiriman berkas. Setelah berkas selesai, berkas yang di minta akan langsung dikirim ke alamat yang dituju oleh driver. Tentunya hal ini sejalan dengan yang di katakan Rogers pada karakteristik relative advantage karena inovasi pelayanan Go Dok ini memiliki keuntungan di antaranya memudahkan masyarakat dengan tidak perlu lagi datang langsung ke kantor dinas kependudukan dan catatan sipil dan mengatri panjang untuk mengurus administrasi kependudukan. Program inovasi pelayanan Go Dok ini tentunya menjadi terobosan baru di Dinas Kependudukan Dan Catatan Sipil untuk meminimalisir keberadaan calo dan pungli.

b. Compability (kesesuaian)

Kesesuaian atau compability yaitu karakteristik inovasi kedua yang dikemukakan oleh Rogers. inovasi yang sebelumnya sudah ada juga tentunya sesuai dengan kebutuhan. Inovasi yang konsisten dengan nilai nilai yang berlaku. Bisa disebut juga inovasi yang sebelumnya sudah ada dimana untuk pembuatan KTP, KK, Akta Kelahiran, Akta Kematian dan KIA harus menempuh beberapa syarat dan juga waktu yang lama setelah pengajuan dokumen antri yang panjang dan juga biaya yang tidak murah merupakan bagian proses transisi dari inovasi baru GO-DOK agar dapat memudahkan segala kebutuhan administrasi kependudukan yang lebih cepat dan mudah.

Hal ini sesuai dengan pendapat Rogers bahwa inovasi yang dapat memudahkan dan juga me nyesuaikan dengan kebutuhan masyarakat inovasi pelayanan GO-DOK tentunya dapat diterima oleh masyarakat jika pemerintah atau petugas dari Dinas Kependudukan dan Catatan Sipil dapat membantu terkait sosialisasi prosedur pembuatan dokumen kependudukan melalui GO-DOK serta fungsi dan kegunaan GO-DOK.

\section{c. Complexity (kerumitan)}

Kerumitan memahami atau complexity merupakan indicator ke tiga dalam karakteristik inovasi menurut Rogers. yaitu kerumitan memahami dalam menggunakan inovasi yang baru dan prosedurprosedur yang harus dilakukan. Inovasi pelayanan GO-DOK bukanlah hal yang rumit karena prosedurnya yang tidak sulit tujuan pelayanan GO-DOK untuk memudahkan masyarakat dalam mengurus administrasi kependudukan dengan hanya melalui pengiriman berkas secara langsung melalui nomor Whatsapp Disdukcapil tanpa harus ke kantor kecamatan atau kantor Disdukcapil dan melalui proses antrian terlebih dahulu. Layanan ini diproses di disduk akan selesai dalam 1 jam paling lambat dalam 24 jam setelah melakukan pengiriman berkas. Setelah berkas selesai, berkas yang di minta akan langsung dikirim ke alamat yang dituju oleh driver.

Dari hasil observasi dan wawancara bahwa inovasi pelayanan GO-DOK dirasa tidak ada kerumitan sama sekali. Karena pemohon hanya perlu untuk mengirim berkas yang diperlukan ke nomor Whatsapp Disdukcapil. Pada umumnya masyarakat di era digitalisasi ini sebagian besar sudah menggunakan smartphone dan menjadikan media Whatsapp sebagai media komunikasi baru pengganti Short Message Service (SMS).

\section{d. Trialability (kemampuan uji coba)}

Kemampuan untuk diuji cobakan atau trialability. Indicator keempat dari karakteristik inovasi ini yaitu suatu inovasi dimana dapat diuji cobakan dalam batas tertentu. Kemampuan untuk dapat diuji bertujuan untuk mengurangi ketidakpastian dalam inovasi pelayanan yang bersangkutan. 
Tabel 3.1

Data Penerimaan Layanan GO-DOK

\begin{tabular}{|c|l|c|l|c|}
\hline \multirow{2}{*}{ No } & \multicolumn{2}{|c|}{ Desember 2019 } & \multicolumn{2}{c|}{ Januari 2020 } \\
\cline { 2 - 5 } & $\begin{array}{l}\text { Jenis } \\
\text { Dokumen }\end{array}$ & Banyak & $\begin{array}{l}\text { Jenis } \\
\text { Dokumen }\end{array}$ & Banyak \\
\hline 1 & KIA & 409 & KIA & 300 \\
\hline 2 & SUKET & 20 & SUKET & 30 \\
\hline 3 & Kartu Keluarga & 1 & Kartu Keluarga & 5 \\
\hline 4 & KTP & 106 & KTP & 309 \\
\hline 5 & Update NIK & 2 & Update NIK & 10 \\
\hline 6 & Akta Kelahiran & 1 & Akta Kelahiran & 5 \\
\hline
\end{tabular}

Sumber: Diolah Peneliti, 2020

Layanan inovasi GO-DOK telah diuji coba pada bulan Oktober 2019 namun masyarakat belum banyak yang memanfaatkannya. Karena memang masyarakat masih ragu pada pelayanan ini terkait dengan aman dan tidaknya dokumen yang dikirimkan. Karena dokumen yang di kirim merupakan dokumen identitas yang khawatir jika disalahgunakan. Tetapi untuk keterjaminan aman tidaknya dokumen, Kepala Bidang Pemanfaatan Data dan Inovasi Pelayanan menjamin dokumen aman dan tidak dapat disalah gunakan. Karena dokumen dikirim hanya pada satu nomor yaitu nomor Whatsapp Disdukcapil.

Hal tersebut sejalan dengan teori Rogers pada indikator trialability (kemungkinan dicoba) yang menyebutkan bahwa sebuah produk inovasi harus melewati fase uji publik dimana setiap orang atau pihak mempunyai kesempatan untuk menguji kualitas dari sebuah inovasi. Setelah melewati fase uji publik dimana setiap orang atau pihak mempunyai kesempatan untuk menguji kualitas GO-DOK maka ditemukan beberapa keunggulan yaitu Masyarakat tidak perlu datang dan mengantri di kantor Disdukcapil, Biaya pengiriman dokumen gratis dan meminimalisir keberadaan Calo dan Pungli. Selain memiliki keunggulan, inovasi pelayanan GO-DOK juga mempunyai kelemahan yaitu Operator call centre tidak dapat bertugas sebagaimana mestinya sebagai verifikator dokumen karena harus menjawab pertanyaan pesaan yang masuk, Semua pesan yang masuk tidak terdokumentasi oleh sistem, dikarenakan layanan GODOK sepenuhnya menggunakan WhatsApp dan Masyarakat atau pemohon tidak dapat mengetahui status atauprogress dari layanan adminduk yang sedang di urus.

\section{e. Observability (kemudahan diamati)}

Observability yang mempunyai arti kemudahan untuk diamati yaitu indikator ke lima dari karakteristik inovasi dalam teori Rogers. Dimana kemudahan untuk diamati pada inovasi pelayanan GO-DOK ini menilai sejauh mana hasil suatu inovasi terlihat oleh orang lain, semakin mudah bagi individu untuk melihat sebuah hasilnya semakin besar kemungkinan mereka untuk mengadopsi. Pelayanan inovasi GODOK ini dapat diimplementasi oleh seluruh lapisan masyarakat. setelah melihat prosedur/proses pelayanan inovasi GO-DOK, tentunya keseluruhan proses dengan mudah dijalankan ataupun diamati. 
Sejauh mana pelayanan inovasi GO-DOK ini dapat terlaksana dan memberika keuntungan serta kemudahan bagi masyarakat yang ingin membuat berbagai macam kebutuhan dalam pembuatan administrasi kependudukan. Inovasi GO-DOK memiliki prosedur yang mudah dipahami dan juga tidak berbelit-belit. Tentunya memberi kemudahan bagi pegawai dan juga masyarakat dalam mengimplementasikan inovasi pelayanan GO-DOK ini. Guna melakukan pelayanan yang efektif dan efisien GO-DOK dianggap sebagai inovasi pelayanan yang berdampak positif bagi masyarakat. Karena layanan ini memudahkan untuk tidak mengantri dan juga menghemat biaya.

\section{Simpulan}

Pelaksanaan inovasi pelayanan public Go Dokumen ditinjau dari pembahasan. 1) Relative advantage bahwa inovasi pelayanan public GODOK tentunya memiliki keunggulan yang baru dalam pelayanan public dengan mempermudah jalur birokrasi dalam pembuatan administrasi kependudukan. 2) Compatibility bahwa inovasi pelayanan public GODOK mempunyai kesesuaian dengan inovasi yang sebelumnya digantikan. inovasi yang dapat memudahkan dan juga menyesuaikan dengan kebutuhan masyarakat inovasi pelayanan GODOK tentunya dapat memberikan prosedur yang memudahan kepada masyarakat. 3) Complexity atau kerumitan memahami dalam penggunaan inovasi GO-DOK. Inovasi pelayanan GO-DOK dirasa tidak ada kerumitan sama sekali karena pelayanan ini dipermudah dengan adanya media online. 4) Trialability atau kemampuan uji coba layanan go dok ini di uji coba sejak tangga 9 oktober 2019 namun masyarakat belum banyak memanfaatkannya. 5) Observability semakin mudah bagi individu untuk melihat sebuah hasilnya semakin besar kemungkinan mereka untuk mengadopsi. Pelayanan inovasi GODOK ini dapat diimplementasi oleh seluruh lapisan masyarakat. setelah melihat prosedur/proses pelayanan inovasi GO-DOK, tentunya keseluruhan proses dengan mudah dijalankan ataupun diamati.

\section{Referensi}

Dwiyanto, A. (2010). Manajemen Pelayanan Publik: Peduli, Inklusif, dan Kolaboratif. Yogyakarta: Gadjah Mada University Press

Hardiyansyah. (2018). Kualitas Pelayanan Publik: Konsep, Dimensi, Indikator Dan Implementasinya. Yogyakarta: Gava Media.

Jordan, B. (2006). Public Service and The Service Economy. Journal of Social Policy..

Junior, M.P. (2016). Inovasi Pelayanan Publik (Studi Kasus Perizinan Penanaman Modal Di BPPT Kota Semarang). Jurnal Ilmu Pemerintahan FISIP UNDIP Semarang).

Kurniawan, A. (2005). Transformasi Pelayanan Publik. Yogyakarta:Pembaharuan.

Mirnasari, R. M. (2013). Inovasi Pelayanan Publik UPTD Terminal Purabaya- Bungurasih. Kebijakan Dan Manajemen Publik.

Muluk, K. (2008). Knowledge Management. Malang: Bayumedia Publishing.

Rogers, E. M. (1983). Diffusion of Innovations. New York: Macmillan Publishing Co.Inc.

Spicker, P. (2009). The Nature of a Public Service. International Journal of Public Administration: 32(11). 970-991

Sugiyono. (2018). Metode Penelitian Kuantitatif, Kualitatif. Bandung: Alfabeta. 